\title{
Study of Ion Beam Sputtering using a Glow Discharge Ion Source
}

\author{
M.M. Abdelrahman \\ Accelerators \& Ion Sources Department, Nuclear Research Center, \\ Atomic Energy Authority, P.O. Box: 13759 Inchas, Cairo, Egypt.
}

(Received on 25 July, 2009)

\begin{abstract}
In this work, sputtering yield in a glow discharge ion source system has been determined using the operating parameters of the ion source. The sputtering yield is found to be varied between 0.4 to 1 atoms removed per incident ion for nitrogen while for argon between 0.2 to 1.3 atoms removed per incident ion. The feature of this ion source is high output ion beam current and small size. Operation of the ion source is quite simple since a stable discharge can be obtained within a large range of main parameters such as, discharge voltage, discharge current and gas pressure. Also, beam profile for argon ion beam produced from the glow discharge ion source at $I_{d}=2,3 \mathrm{~mA}$ (discharge current) using argon gas with different gas pressures has been investigated.
\end{abstract}

Keywords: Glow discharge ion source, sputtering yield, argon gas pressure, plasma production.

\section{INTRODUCTION}

Sputtering is a process whereby atoms are ejected from a solid target material due to bombardment of the target by energetic ions. It is commonly used for thin-film deposition, etching and analytical techniques. Physical sputtering is driven by momentum exchange between the ions and atoms in the material, due to collisions [1]. The average number of atoms ejected from the target per incident ion is called the sputter yield and depends on the ion incident angle, the energy of the ion, the masses of the ion and target atoms, and the surface binding energy of atoms in the target. The incident ions set off collision cascades in the target, when such cascades recoil and reach the target surface with an energy above the surface binding energy, an atom can be ejected. When a target is bombarded with fast heavy particles, erosion of the target material occurs: this is termed sputtering [2-7]. The glow discharge in sputtering is significantly dependent on the work function of the target material and pressure of the environmental gas [8]. Sputtered atoms ejected into the gas phase are not in their thermodynamic equilibrium state, and tend to deposit on all surfaces in the vacuum chamber. A substrate (such as a wafer) placed in the chamber will be coated with a thin film. Sputtering usually uses argon plasma. In the present work, we have studied the profile of the argon beam produced from the glow discharge ion source and determined the sputtering yield with the aid of the different operational parameters using argon and nitrogen gases at the same gas pressure.

\section{EXPERIMENTAL SETUP}

A schematic diagram of the glow discharge ion source and its associated electrical circuit is shown in Fig. 1. This glow discharge ion source has been described before [9]. It consists of aluminium Pierce shape anode with small aperture to confine the discharge and aluminium plane cathode. The anode has an internal diameter of $28 \mathrm{~mm}$ at the upper side and $10 \mathrm{~mm}$ diameter at the lower side and its length $17 \mathrm{~mm}$. The aluminium cathode has an aperture of diameter $1.5 \mathrm{~mm}$ and length $5 \mathrm{~mm}$. Both the Pierce anode and the plane cathode are immersed in an insulator of Perspex material.

The collector (Faraday cup) is situated at a distance of 5 $\mathrm{cm}$ from the ion-exit aperture of the cathode and used to measure the output ion beam current. The working gas is admitted to the ion source through a hose fixed in a Perspex flange at the upper side of the anode. A $10 \mathrm{kV}$ power supply is used for initiating the discharge (glow discharge) between the anode and the cathode.

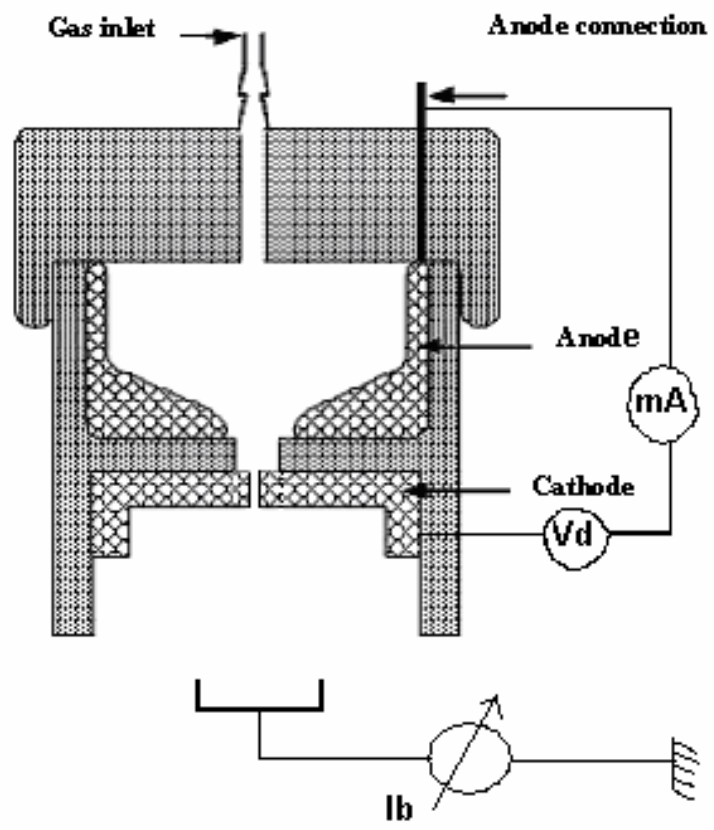

FIG. 1: Schematic diagram of the ion source and its associated electrical circuit [9].

A complete vacuum system is used to evacuate the ion source chamber. It consists of stainless steel silicon oil diffusion pump provided with electrical heater and backed by rotary fore vacuum pump. The rotary pump is used to evacuate the system with ultimate pressure of $10^{-2}$ to $10^{-3} \mathrm{mmHg}$, while the silicon oil diffusion pump is used to yield very low pressure in the ion source vacuum chamber of the order of $10^{-5} \mathrm{mmHg}$. The silicon diffusion pump is surrounded by water tubes for cooling during the operation. A liquid nitrogen trap is fixed between the ion source chamber and the silicon oil diffusion pump in order to prevent the silicon vapour from entering the ion source chamber. The working gas is 
transmitted to the ion source from a gas cylinder through a needle valve to regulate the rate of gas flow.

\section{EXPERIMENTAL RESULTS}

In this work, the distance between the anode and the cathode, $d_{A-K}$ is fixed at the optimum value [9] for stable discharge current and high output ion beam current. The discharge characteristics of the glow discharge ion source such as, discharge voltage, discharge current and output ion beam current are investigated using nitrogen and argon gases. Also the sputtering yield is determined using the experimental results for nitrogen and argon gases on stainless steel material (target).

\section{1- Ion Source Properties}

Figure 2 shows the relation between the discharge current, $I_{d}$, and the discharge voltage, $V_{d}$, at different gas pressures, $\mathrm{P}$, using nitrogen gas. It is clear that an increase of the discharge voltage was accompanied by an increase of the discharge current, where at the same discharge voltage; the discharge current is higher at high pressure than that at low pressure. Figure 3 shows the relation between the output ion beam current, $I_{b}$, and the discharge current, $I_{d}$, at different nitrogen gas pressures, P. It is obvious that, when the discharge current increases, the output ion beam current increases and high output ion beam current was obtained at low pressures than that at high pressures.

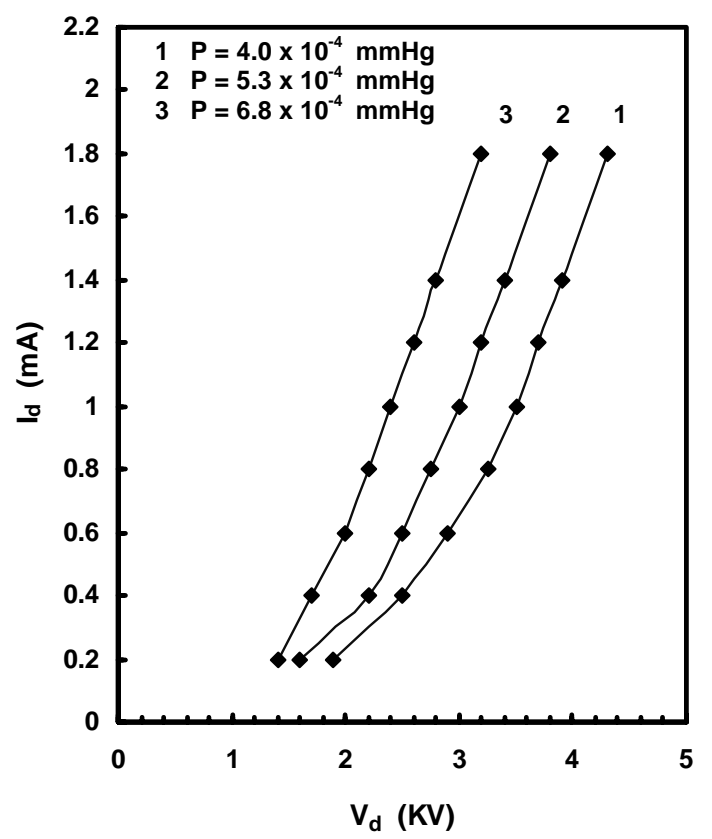

FIG. 2: Discharge current versus discharge voltage at different pressures using nitrogen gas.

Figure 4 shows the relation between the discharge current, $I_{d}$, and the discharge voltage, $V_{d}$, at different argon gas pressures $P$. It is clear that an increase of the discharge voltage

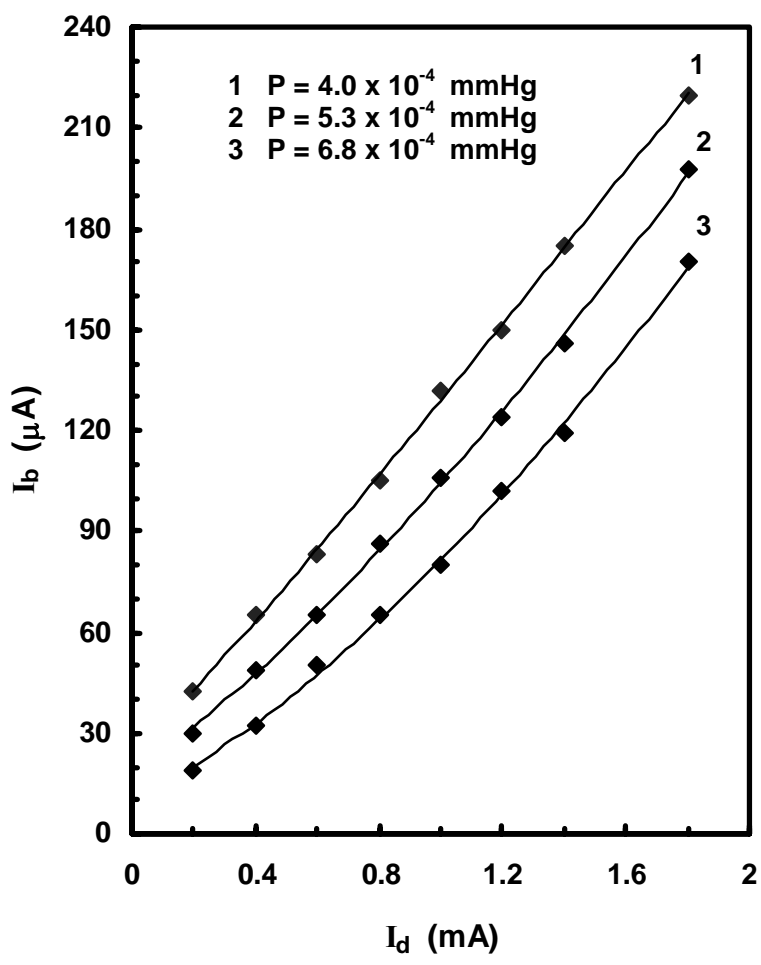

FIG. 3: Output ion beam current versus discharge current at different pressures using nitrogen gas.

was accompanied by an increase of the discharge current, where at the same discharge voltage; the discharge current is higher at high pressure than that at low pressure.

Figure 5 shows the relation between the output ion beam current, $I_{b}$, and the discharge current, $I_{d}$, at different gas pressures, $\mathrm{P}$, using argon gas. It is obvious that, when the discharge current increases, the output ion beam current increases and high output ion beam current was obtained at low pressures than that at high pressures.

Fig. 6 shows beam profile for argon ion beam produced from the glow discharge ion source at $I_{d}=2 \mathrm{~mA}$ using argon gas. It is clear that the maximum value of the output ion beam is obtained at the center of the target at pressure equal to $8 \times 10^{-4} \mathrm{mmHg}$ and it decreases by increasing the pressure.

Fig. 7 shows beam profile for argon ion beam produced from the glow discharge ion source at $I_{d}=3 \mathrm{~mA}$ using argon gas. It is clear that the curves have the same behaviour as shown in Fig. 6 but the maximum value of the output ion beam increases by increasing the discharge current. Figs 6 and 7 show the beam profile for argon gas at low voltage $\left(1.8 \mathrm{kV}, 2.05 \mathrm{kV}\right.$, respectively) and high pressure $\left(1.1 \times 10^{-3}\right.$ $\mathrm{mmHg}$ and $9 \times 10^{-4} \mathrm{mmHg}$, respectively). It is clear that , the beam profile is uniform distribution which is required in many field of industrial applications as, cleaning of the materials, sputtering etc..(Broad Beam Surface). Figs 6 and 7 show beam profile at high voltage $(3 \mathrm{kV}$ and $3.5 \mathrm{kV}$, respectively) and low pressure $\left(8 \times 10^{-4} \mathrm{mmHg}\right)$. It was found that, a peak appeared which is suitable for a thin focused ion beam and is required for ion beam applications of a narrow area surface. The increase of the extraction voltage (acceler- 


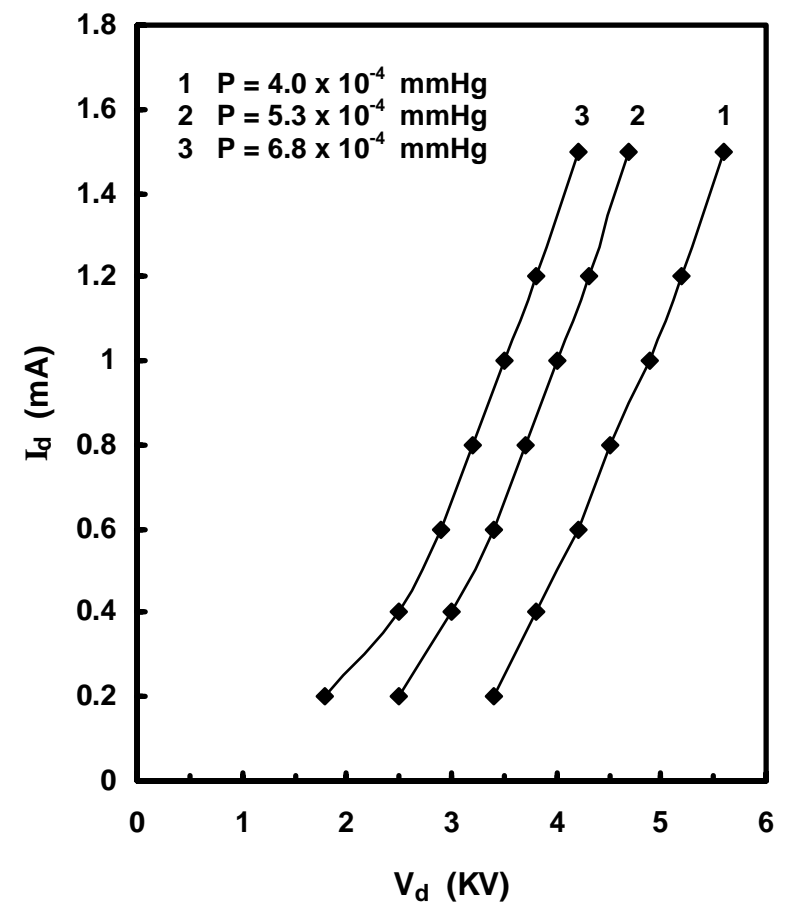

FIG. 4: Discharge current versus discharge voltage at different pressures using argon gas.

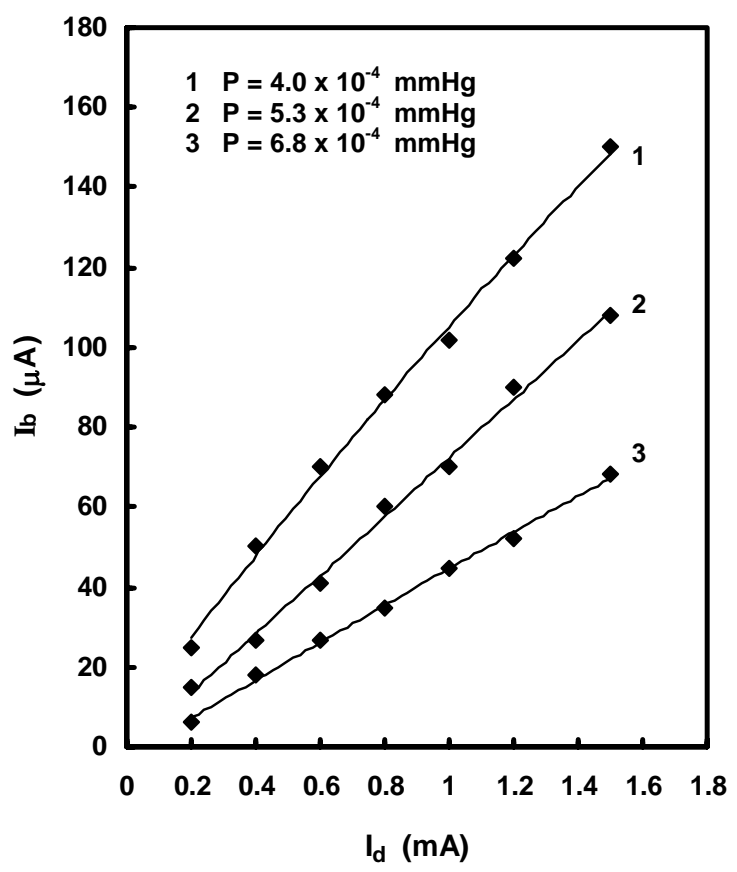

FIG. 5: Output ion beam current versus discharge current at different pressures using argon gas.

ation voltage) decreases the width of the ion beam [10].

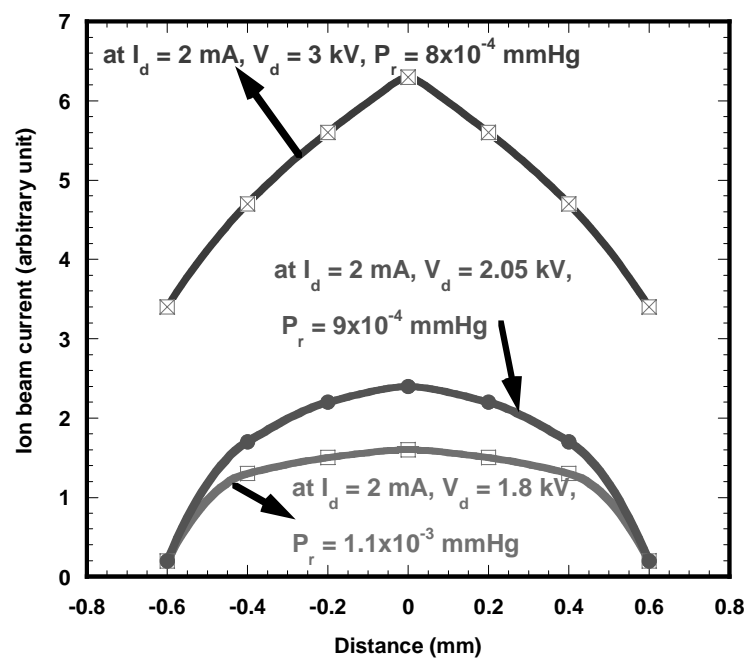

FIG. 6: Beam profile for argon ion beam produced from the ion source at $I_{d}=2 \mathrm{~mA}$.

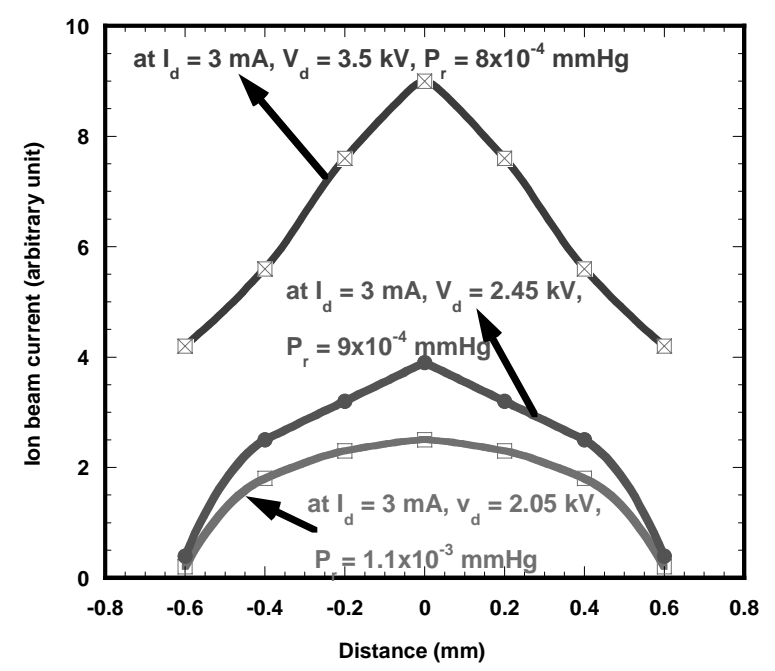

FIG. 7: Beam profile for argon ion beam produced from the ion source at $I_{d}=3 \mathrm{~mA}$.

\section{2 -Determination of the Sputtering Yield}

The rate of sputtering process can be calculated from simple considerations of the volume removed per atom. In particular, the thickness removed per second by ion beam sputtering given by the expression [11]:

$$
\delta=1.66 \times 10^{-24} \cdot \frac{M S}{\rho} \cdot \frac{J_{i}}{e}
$$

where $M$ is the atomic mass of the target atoms, $\rho$ is the density of the sputtered material, $e$ is the charge of the electron, $j_{i}$ is the ion beam current density at the target and $S$ is the sputtering yield (atoms removed per incident ion) given by the relation:

$$
S=\frac{M_{1}}{M_{2}} \frac{\ln W}{W} \frac{1}{\cos \theta}
$$




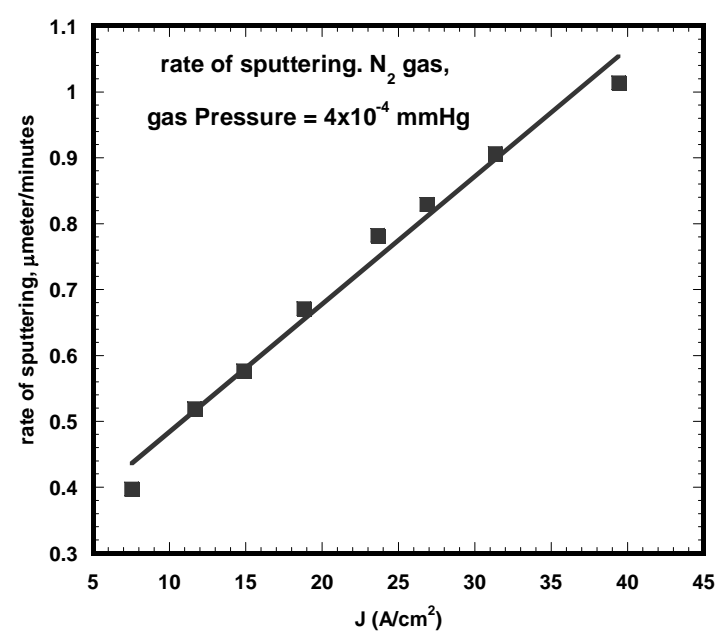

FIG. 8: Relation between the current density, $J$,in $\mathrm{A} / \mathrm{cm}^{2}$ and the rate of sputtering, $\delta$, in $\mu \mathrm{m} / \mathrm{min}$. at $p=4 \times 10^{-4} \mathrm{mmHg}$ for nitrogen gas on stainless steel material (target).

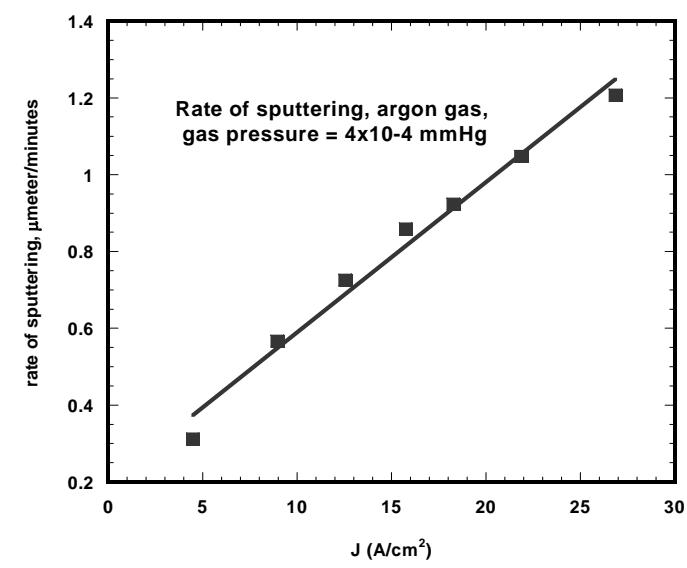

FIG. 9: Relation between the current density, $J$, in $A / \mathrm{cm}^{2}$ and the rate of sputtering, $\delta$, in $\mu \mathrm{m} / \mathrm{min}$. at $p=4 \times 10-4 \mathrm{mmHg}$ for argon gas on stainless steel material (target). where $M_{1}$ is the mass of the incident ion, $M_{2}$ is the mass of the target particle and $W$ is the energy of the incident ion and $\theta$ is the angle between the incident beam and the target. By substituting eq. 2 in eq. 1 , and using the experimental results, the rate of sputtering can be calculated, where in our case $\theta=0$, so $\cos \theta=1$. Figs. 8 and 9 show the relation between the current density, $J$, in $A / \mathrm{cm}^{2}$ and the rate of sputtering, $\delta$, in $\mu \mathrm{m} / \mathrm{min}$. at constant pressure, $P=4 \times 0^{-4} \mathrm{mmHg}$, using pure nitrogen and argon gases. It is clear that at the same current density, the rate of sputtering in case of argon gas is higher than that for nitrogen gas at the same pressure.

\section{CONCLUSION}

In this study, sputtering yield in a glow gas discharge ion source system has been determined using the operating parameters of this ion source. The main features of this ion source are high output ion beam current and small size. Operation of this ion source is quite simple since a stable discharge can be obtained within a large range of main parameters such as, discharge voltage, discharge current and gas pressure. The sputtering yield is found to be varied between 0.4 to 1 atoms removed per incident ion for nitrogen while for argon between 0.2 to 1.3 atoms removed per incident ion. Also, beam profile for argon ion beam produced from the glow discharge ion source at $I_{d}=2,3 \mathrm{~mA}$ (discharge current) using argon gas with different gas pressures has been investigated. Indeed, it is found also that, at the same current density, the rate of sputtering in case of argon gas is higher than that for pure nitrogen gas. This ion source can be used for etching, sputtering and micro-machining applications.

[1] R.Behrisch and W.Eckstein; Sputtering by Particle bombardment: Experiments and Computer Calculations from Threshold to Mev Energies. Springer, Berlin (eds.) (2007).

[2] F. Aumayr and HP. Winter, Phil. Trans. R. Soc. Lond. A 362, 77-102 (2004).

[3] J. F. Ziegler, J. Appl. Phys, 85, 1249-1272 (1999).

[4] H. Gnaser, Low-Energy Ion Irradiation of Solid Surfaces, Springer- Verlag Berlin Heidelberg, Germany, 1999.

[5] Tatsuya Banno et al, Vacuum, 80, 667-670 (2006).

[6] S.Han et al, Vacuum, 78, 539-543 (2005).

[7] L. He et al, Nanotechnology, 19, 445610 (2008).
[8] K. Hine et al, The Second International Symposium on Atomic Technology IOP Publishing, Journal of Physics: Conference Series 106,012019 (2008).

[9] M.M.Abdel Rahman, A.G.Helal, O.A.Mostafa and F.W.Abdel Salam, Journal of Nuclear and Radiation Physics, Vol. 3, No. 1, (2008).

[10] S.G. Zakhary, Rev. Sci. Instrum. 66, 12, December (1996).

[11] H.L.Garvin, Paper presented at KODAK Microelectronics Seminar, San Diego, Calefornia, Dec.11-12 (1972). 